\title{
Clustering the agricultural SME sector in Eastern Highlands, Zimbabwe
}

Ngoni Munyawarara ${ }^{1 *}$, Krishna K. Govender ${ }^{2}$

School of Management, IT and Governance, University of KwaZulu-Natal ${ }^{1 * 2}$

$\underline{\text { ngonimuyawarara70@gmail.com }}^{1^{*}}$, krishnagovender@gmail.com $^{2}$

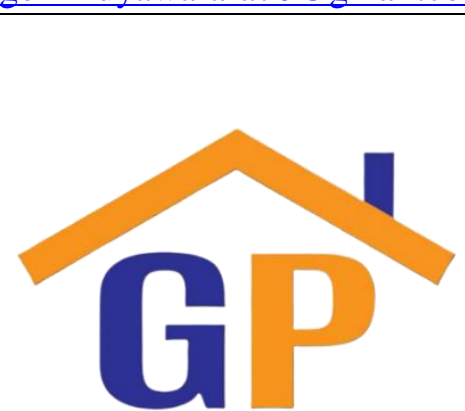

Article History

Received on 24 February 2020

$1^{\text {st }}$ Revision on 12 March 2020

$2^{\text {nd }}$ Revision on 29 April 2020

$3^{\text {rd }}$ Revision on 14 May 2020

Accepted on 29 June 2020

\begin{abstract}
Purpose: The clustering concept focuses on agricultural SME development. It is a strategy seeking to stimulate entrepreneurship growth and integrating broad SME structures that help to create value and competitiveness to enhance food security and community development in less developed countries.
\end{abstract}

Research Methodology: This study investigated the impact of clustering the agricultural SME sector in Zimbabwe and it was restricted to the Eastern Highlands. The population consists of agricultural SMEs in Eastern Highlands. A methodological design survey on agricultural SME clusters was carried out using a purposive sampling technique, which selected a sample size with a total of 60 agricultural SMEs.An explanatory correlation analysis was used to analyze the data.

Results: The study showed that clusters have a significant effect on agriculture SME the development in Zimbabwe. The study results indicated that clustering SMEs improve their competitiveness and market share growth, which is a rationale for economic growth. Findings also showed that clustering SMEs restructure their radical growth. These results further indicated that most agricultural SMEs are crippled due to a lack of cluster centers in their areas to enable them to compete and expand their market share

Limitations: A solitary research tool seems to have weakened the study.

Contribution: Clustering the agricultural Small and Medium Enterprises (SMEs) is very important because it promotes their competitiveness, productivity, market share, success, as well as community development and industrialization. Therefore this study contributed largely to the literature.

Keywords: Clustering, Agricultural, SMEs, Community development, Food security

How to cite: Munyawarara, N., Govender, K. K. (2020).

Clustering the agricultural SME sector in Eastern Highlands,

Zimbabwe. International Journal of Financial, Accounting, and

Management, 1(4), 247-255.

\section{Introduction}

Clustering the agricultural SMEs is increasingly recognized as a significant driver of economic growth, skills development, and productivity. This management strategy is a key aspect of developing poor communities and improving agricultural productivity to ensure food security is attained (Delgado, Porter, \& Stern, 2014; ACET, 2015). Therefore the ultimate objective of clustering businesses facilitates the development of the informal agricultural activities. This further, in turn, helps to identify high impact opportunities for SMEs which leads to their drastic development . It is against this baseline that governments are playing critical roles in cluster programs in communities 
seeking to stimulate SME development (Bass, 2012) since they have a significant impact on food security and agricultural development.

This prudent approach contributes to economic development and food security, as Mangudya, (2017), ZimVac (2013) and FAO (2017) agree that the agricultural sector is the panacea for industrialization. However Nyamutowa, Masunda, \& Mupaso (2014) further consider that clustering the agricultural SME sector in Zimbabwe provides a fertile ground for skills development, proximities to resources, and increased competitiveness. As such clustering of agricultural SMEs is recognized as the principal means of modern SME diversification, tradeoffs, and sustainability. Studies by Wolfe \& Gertler (2016) and Hervas-Oliver, Gonzalez, Caja \& Sempere-Ripoll (2015) on clustering SMEs have shown that their dynamics increase their productivity and the SME owners benefit a lot more through cost savings which result from discounts at cluster workspaces (Katua, 2014). Further preceding studies by ACET (2015) and ILemona (2013) opine that agricultural SMEs generate employment to alleviate poverty in communities and entrepreneurs and become self-sustaining.

In the Zimbabwean scenario, lack of clustering SMEs is the greatest obstacle that is grappling agricultural development. Yet on the other hand a clustering strategy is an important catalyst for SME imminent development. Although some clusters are readily available, several SMEs cannot fit into the available co-location workspaces (Kamoyo, Mavhima, and Muranda 2014). (Fornahl, Hassink, \& Menzel (2015). Considering that the agricultural sector is poorly performing, therefore clustering SMEs is equally important in promoting them to be competitive and improve their market share in the endeavor to increased food production, as a measure to reduce hunger and poverty. As such, clustering has shown a significant contribution towards developing the agricultural SMEs through a wide range of clustering initiatives such as innovation and incubation hubs (Uyarra \& Ramlogan, 2012; Delgado et al , 2014). It is against this approach that the main objective of this research work is to investigate and attempt to understand the extent of clustering the agricultural SME sector in Zimbabwe.

\section{Literature review and hypothesis development}

\subsection{Importance of the agricultural SMEs}

In many instances, agriculture has become a key priority sector for food provision and poverty reduction (Food and Nutrition Council, 2014) Therefore the agricultural SMEs transform economies around the world through the provision of basic food to people and raw materials to industries, primarily seeking to stimulate community development and industrialization. In America, agriculture clustering has greatly helped food security (WFP, 2014). Thus the focus of employing clustering programs by every government is to ensure that agriculture is developed (Nyamutowa et al, 2014). Even though the agricultural sector faces aggressive competition from various elements of globalization, it has remained a vital sector in combating hunger and poverty reduction in communities (ILemona, 2013). This is evident in countries such as Central, Eastern, and SouthEastern Asia and Latin America which have attained food security through promoting agricultural cluster programs (FAO, 2017). In this case, the Cuban agricultural revolution has optimized intensive and meticulous cluster initiatives and doubled its food security (WFP, 2014).

Even though, the agricultural SMEs have remained the most important sector that reduces poverty and hunger. It is employing in between 60-80 percent of the economically active population in Africa, clustering the agricultural SMEs has stayed relatively slow. This is due to numerous and wide-ranging matters, but what is understood is that clustering SMEs is even more important since they end up producing higher crop yields per hectare than larger farms (Fornahl et al, 2015; Katua, 2014). Therefore, the value of agriculture is unlocked through clustering SMEs in the agrarian sector as a measure to enhance food security (Food and Nutrition Council, 2014).

Explicitly, this indicates that clustering SMEs in the agrarian sector provides a linchpin for allencompassing national economic development. As such, to be more specific, a positive change in the SME cluster policy is the main focus of government intervention in trying to reap out the best benefits from the agrarian SMEs' development (OECD, 2016). To this end, government cluster initiatives create conditions that encourage competition among the SMEs. It is against this backdrop that turning 2020 | International Journal of Financial, Accounting, and Management/ Vol 1 No 4, 247-255 
around the Zimbabwean agrarian SMEs depends on clustering and diverse government policies and strategies.

\subsection{Concept of clustering and the agricultural SME sector}

The major purpose of clustering the agricultural SMEs is to help them increase their yields. Given the agricultural SME primary goal of contributing to food security, SMEs are seen as critical in achieving economic development. However this sector is an unregulated type of agro-based business, though it iss an important means of improving livelihoods and as well as community development (ACET, 2015). According to Barbour \& Llanes (2013) and Gancarczyk (2015), agricultural SMEs are recognized worldwide as a key means of food security and economic development. This view appears to be supported by Wolfe \& Gertler (2016) who argue that promoting clusters in developing countries foster agriculture and economic development to alleviate cyclical poverty and hunger (ILemona,2013; Chinamasa, 2016).

In far Europe, SMEs employ no more than 500 employees (ASMEC, 2013). However, Cant \& Wiid (2013) define SMEs as enterprises that survive on social working capital and their benefits include; contributions to the economy in terms of output of goods and services, and creation of jobs at relatively low capital cost (Le Roux \& Bengesi, 2014). The agricultural clusters reduce income disparities and improve employee skills as a basis for increasing their development by improving their forward and backward linkages. In Zimbabwe, an SME sector is defined as having a workforce of between 2 and 300 employees. SMEs do illegal farming activities and virtually any of them are unregistered. However, geographically, clustering the SME sector creates diverse opportunities such as market intensity and adaptation of appropriate technological approaches offers them a new breaking ground for entrepreneurial skills development (ILemona, (2013; Le Roux \& Bengesi, 2014).

In this domain, Kamoyo et al (2014) suggest that clustering addresses the following SME sector gaps; Lack of management by entrepreneurs as many of them start agricultural SMEs with no knowledge and experience, hence clustering them creates an opportunity for their competitiveness performance through intensification of networking and mentoring.

- Low mechanization technologies.

- Low markets

- Lack of resources such as capital and human labour.

\subsection{Competitiveness of agricultural SME sector}

The competitiveness of an SME is largely regarded as the rational process by which entrepreneurs know that their entities are bound to be successful and increase their market share (Jason, 2012). The scale of the competitiveness of an SME in strategic management is important in understanding a range of organizational strategies necessary for organizational effectiveness. This is useful in this sector where there is both scope for reinvention of the clustering strategy $s$ to suit the context and the need to grow the market share and wads off stiff competition (Katua, 2014). Therefore the essence of this study concerns key variables to attain SME development and agriculture development through clustering the agrarian SMEs since the food consumption rate is rising by the day in communities (ACET, 2015). Besides, this sector plays a strategic function in the increase of food production and the rising of per-capita income.

To this end, the 21stcentury has been increasingly focusing on clustering SMEs (Fornahl, et al (2015). In line with this general belief, the government introduced cluster programs to restore macroeconomic stability and productivity in all food and agricultural SME initiatives (ZimVac, 2013; Food and Nutrition Council, 2014). Therefore the approach to food security is the constitutional right of citizens and the absorption of scattered SMEs into clusters helps them to radically grow fast and is a measure seeking to increase food nutriment in communities. Pioneer studies have suggested that clustering SMEs is better placed for the development and resource distribution in communitiesTherefore the approach to food security is the constitutional right of citizens and the 
absorption of scattered SMEs into clusters helps them to radically grow fast and is a measure seeking to increase food nutriment in communities. Pioneer studies have suggested that clustering SMEs is better placed for the development and resource distribution in communities.

It is in this context that comprehensive agricultural cluster programs are needed to ensure the development and competitiveness of SMEs and aid in agricultural transformation (WFP, 2014). The locus of clustering takes stock of progress made towards achieving the internationally established hunger and poverty reduction targets (ACET, 2015). Hence, the food insecurity eradication and the development of agrarian SMEs should remain a key commitment of decision-makers at all levels. The new SME entrants into farming lack government cluster support on how to develop. Therefore, the rationale behind clustering SMEs is to promote high-level SME labor-intensive activities.

\subsection{Nature of clustering}

Cluster policy tools are fashionable for boosting SME competitiveness (OECD, 2016). Researchers suggest that clusters vary significantly across nations. This study investigated the impact of clustering SMEs in Zimbabwe to foster their competitiveness and reduce the gap in cost-effective development. Therefore, clustering agricultural SMEs is lagging far behind than formal businesses (Barbour \& Llanes, 2013). The Ministry of SMEs recently introduced the Clustering Policy to promote the SME sector to grow and make entrepreneurs gain experience and become empowered to reform, re-brand and re-capitalize SMEs to develop.

The clusters operate as a unit to nurture SMEs into large companies (Kamoyo et al, 2014) and it refers to working spaces in a geographical area, which cooperate and establish close linkages and alliances among SMEs seeking to improve their competitiveness (Delgado et al, 2014). Although it is a difficult task to explain the definition of clustering, various characterizations have been proposed in the review of the literature. However clustering has become a solution that addresses poorly performing SMEs.As such the need to improve their development has emanated from a rapidly changing economic, social, and political environment. The literature suggests that clustering SMEs have diverse expectations towards the potential benefits of SMEs to gain better access to financing, training activities, and information/knowledge switch over, and to collaborate with research and training (Barbour \& Llanes, 2013). Thus clustering agricultural SMEs has important implications for agriculture and community development.

In other words clustering is defined as a development tool that grants or provides the SME sector services and assists in expanding or establishing agricultural activities to improve food security. Cant \& Wiid (2013) traditionally not served by the conventional centers. Clustering in its simplest form is a representation of the sector density to stimulate SME development. However, clustering is mostly used in developing economies where the SME sector does not have access to other resources necessary to stimulate their development. Thus clustering programs recognize the SME agricultural SMEs which are excluded or denied access to cluster (Delgado et al, 2014). The main objective of clustering the SME sector according to Kamoyo et al (2014) is to improve their development. They' further state that clustering SMEs help to attract global markets and it encourages competition among them and big companies. The establishment of clusters serves to provide diversified, affordable, and dependable cluster services to increase their high net worth.

In Zimbabwe; the SME cluster inclusion has been recognized as an essential tool for their development. However lacks of access to cluster centers hinder entrepreneurial development. Delgado et al, (2014) agree that access to capital and markets is one of the major problems being faced by the agricultural SME sector in Zimbabwe. Gancarczyk (2015) also argues that insufficient clusters by the SME sector have negative consequences for their development. The idea of promoting clusters aims at providing the SME sector proximity to the market. Kamoyo et al (2014 believe that the promotion of clustering SMEs is justified because it fosters economic development in developing countries. Therefore the main objective of clustering according to Delgado et al (2014) radically develop the informal sector into large companies. 


\section{Research hypotheses}

$\mathrm{H} 1$ : There is a significant relationship between clustering and agricultural SME development in Zimbabwe.

$\mathrm{H} 2$ : There is no significant relationship between clustering and agricultural SME development in Zimbabwe.

\section{Research methodology}

\subsection{Research design}

A quantitative methodology relied on a survey on the insightful investigation of clustering agricultural SMEs. The population of the study consisted of the entire agricultural SMEs in Eastern Highlands (Saunders, Lewis, and Thornhill, 2013). However, the study was restricted to the Eastern Highlands and a purposive sampling technique was used to select SMEs that participated in the study. A total of 60 SMEs constituted the sample size of the study (Mkansi, \& Acheampong, 2012). The primary data consisted of a structured questionnaire which was completed by the respondents. To ensure the validity and reliability of the questionnaire, experts in the field of clustering were consulted to review the questionnaire. A pilot test was conducted before the actual study. An explanatory correlation analysis was used to analyze the data (Silverman, 2013).

\section{The rationale for clustering agrarian SMEs and the study area}

Clustering agricultural SMEs paradigm has originated from scholars in the field of science and management (Delgado et al,(2014). On the other perspective, Gancarczyk (2015) further opines that the aim of clustering the agrarian sector is key to attain food security, improve livelihoods, generates employment to reducing poverty. This argument is revealing that clustering agricultural SMEs contribute significantly to economic development and is dynamic in increasing the performance of SMEs (Katua, 2014). Over the last decade, the Eastern Highlands, in Manicaland province population is dependent on agriculture, and its prime land is buoyed by agrarian activities. (Finmark Trust, 2012; Anseeuw, Kapuya, \& Saruchera, 2012). This agrarian sector accounts for over $30 \%$ of merchandise exports and raw material supplies for the manufacturing sector (Ministry of Agriculture, Mechanization and Irrigation Development, 2014). It is argued that high levels of clustering SMEs' promote higher economies of scale Chinamasa (2016) posits that the culture of SMEs is heavily influenced by clustering to provide food security which underlines the importance of cluster workspaces. The SMEs in the Eastern Highlands have a minute impact on output, leading to reduced turnover inhibiting their development $(\mathrm{FAO}, 2017)$. This has provoked the researcher to explore the impact of clustering the agricultural SME sector in the Eastern Highlands in Zimbabwe (WFP, 2014).

\section{Results and Discussions}

The hypothesis is framed as follows:

H1: There is a significant relationship between clustering and agricultural SME development in Zimbabwe.

The embedded objective of the research was to investigate the relationship between clustering and the development of agricultural SMEs in Zimbabwe (Anseeuw, Kapuya, \& Saruchera, 2012). The use of clusters was hypothesized to develop agricultural SMEs(null hypothesis). The impact of clustering the agricultural SMEs was investigated. An inherent relationship was assumed to exist between these variables. The results from the regression analysis technique supported the hypothesis. That is all the variables had $\mathrm{p}=0.000$ and since $\mathrm{p}<0.05$, the hypothesis was accepted for all variables. To conclude clustering has a positive relationship with the development of agricultural SMEs in Zimbabwe 


\section{Figure 1: Rate of SME Absorption into Agricultural Clusters}

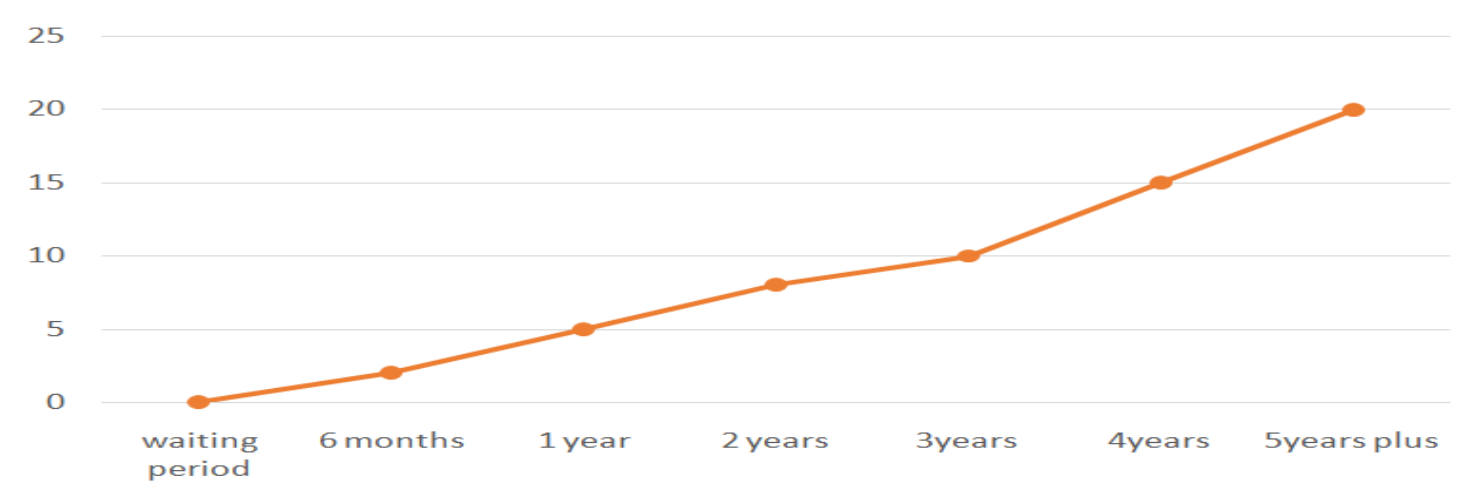

The rate of SME absorption into clusters is relatively low as indicated in Figure 1 above, it is taking longer to place them into clusters hence slowing their development curve. In a single year, 5 of $60(8.33 \%)$ of the participants were absorbed into clusters. Therefore lack of access to cluster hubs is deterring the development of SMEs.Therefore the government should intervene and correct the anomalies as a measure to stimulate the radical development of SMEs in Zimbabwe.

Figure 2: Extent of Clusters in Improving Market Share Development and Competitiveness

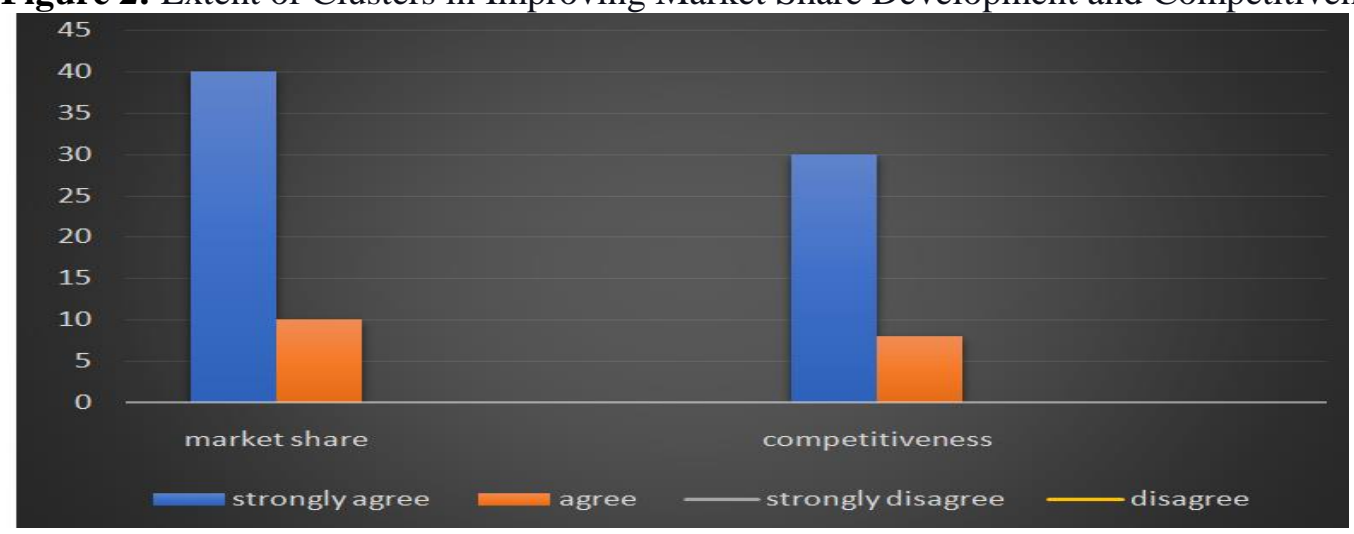

From Figure 2, about 40 participants (66.66\%) of the SMEs in the Eastern Highlands contented that clustering the agrarian SMEs increases their market share and about 35 participants (58.3\%) agreed that it increases their competitiveness to increase their development. The study revealed that there are clustering advantages inclined to the development of agricultural SMEs in the country.

\section{Figure 3: Influence of Clustering on SME Performance and Development}

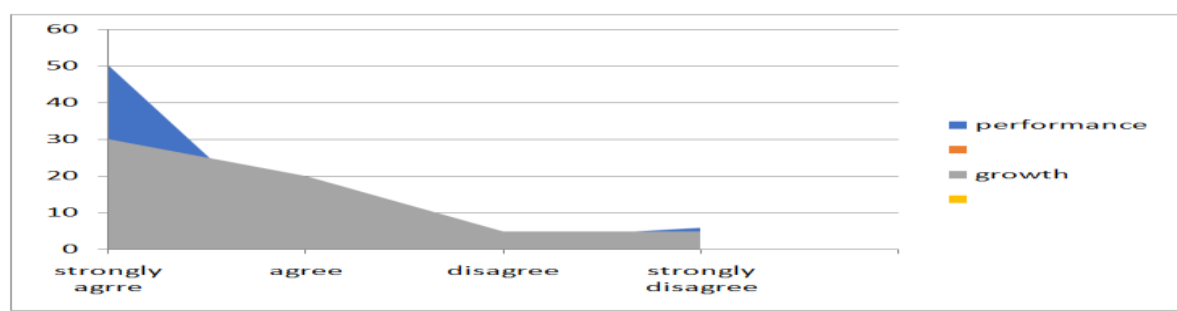

In figure 3 above, 50 of the $60(83.33 \%)$ participants strongly agree that that clustering agricultural SMEs have a strong influence on their performance to ensure food security and nutriment is attained in Zimbabwe. Furthermore 30 of the $60(50 \%)$ participants strongly agreed that clustering influences the rapid and radical growth of SMEs. These results are consistent with Delgado et al (2014) submit that clustering is business management strategies that stimulate catalyze business development. 


\section{Figure 4: Clustering Catalyse Community Development and Industrialization}

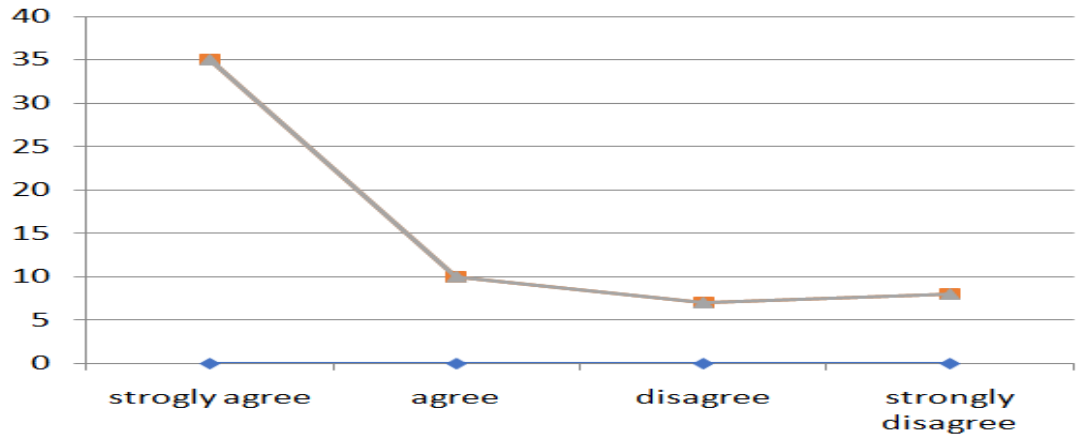

The majority of the participants $(58.33 \%)$ agreed that clustering influence community development and industrialization. This is reflective of the fact that clustering improves livelihoods and infrastructure in developing countries.

\section{Figure 5: Clusters Spur Entrepreneurial Development}

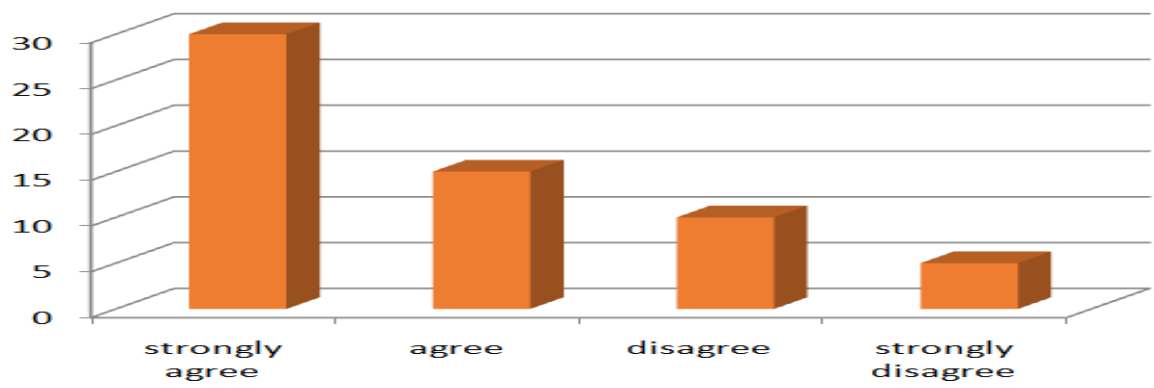

Figure 5 above, establishes that clustering improves SME skills experience and knowledge as evidenced above by 30 of the $60(50 \%)$ participants who strongly agreed that entrepreneurial development is spurred by clustering SMEs (ILemona, 2013; Le Roux \& Bengesi,2014). The present study revealed that there was a statistically significant association existing between clusters and entrepreneurial development to enable SME radical development.

\section{Clustering and SME Development}

A radical development by SMEs is a result of effective clustering initiatives supported by the government. Therefore the study tested the relationship between clustering as the dependent variable and the development of agricultural SMEs in Zimbabwe as the constant or predictor variable (Delgado et al, 2014). Agricultural SMEs in Zimbabwe are strongly influenced by uptake of clusters( Kamoyo et al,2014). This has been evidenced by the hypothesis testing, absorbing more SMEs into clusters to guarantee SME development (Delgado et al, 2014). As seen in this analysis of ( $<<0.05$ ), clusters are important in facilitating agricultural SMEs to develop into transnational companies (Mkansi,\& Acheampong, 2012). However, agricultural SMEs seem to lag as far as being absorbed into clusters in Eastern Highlands to develop into formidable and competitive SMEs (Kamoyo et al, $\underline{2014)}$.

\section{Conclusion}

The study concluded that agricultural SMEs are a vehicle for generating employment and enhancing economic development in Zimbabwe. It was also observed from the study that the role of clustering SMEs increases their growth (Bass, 2012; Delgado et al, 2014). The clustering program in Zimbabwe plays a pivotal role in shaping the development of agricultural SMEs' role in creating employment, opportunities for global markets, community development, and food security in general (Katua, 2014; Nyamutowa et al, 2014; FAO, 2017). However, the rate of adoption of these clusters among entrepreneurs was found to be relatively low. Therefore, it is concluding that there is still a need to absorb more agricultural SMEs into clusters so that they radically develop. In terms of the cluster policy framework, the agricultural SMEs have so much perspective in terms of competing with large 
companies. As such; the government must dedicate more support by availing more cluster programs to enable SMEs to grow their market share. The study revealed a broader clustering theoretical as a tool for facilitating agricultural productivity. In this view, clustering enables the interaction between SMEs and global markets (Wolfe \& Gertler, 2016). This brings in foreign currency which stimulates economic development in Zimbabwe (Le Roux, \& Bengesi, 2014; Chinamasa, 2016). Therefore, further research needs to be conducted to factor of the low utilization of clusters to force agricultural SMEs to become more competitive on a global scale.

\section{Limitation and study forward}

Solitary research tool and lack of funding seem to have weakened the credibility of the study. Therefore further research using mixed methods perhaps will allow the addition of more detailed information to the study topic. As a consequence, a small sample in this study gave a feeble range of findings. Future research could look into the importance of using a bigger sample to help produce inclusive and conclusive SME results.

\section{References}

ACET. (2015). Promoting sustainable rural development and transformation in Africa-Synthesis Report: Accra, Ghana.

American Small to Medium Enterprise Council. (2013). USA: SMEs Facts and Data.

Anseeuw, W., Kapuya, T. \& Saruchera, D. (2012). Zimbabwe's agricultural reconstruction: Present state, ongoing projects and prospects for reinvestment. Development Planning Division, Working Paper Series No. 32, South Africa: Development Bank of Africa.

Barbour, A., \& Llanes, M. (2013). Supporting people to legitimise their agricultural SMEs, Joseph Rowntree Foundation: New York. Canada to China. Journal of Economic Geography, 14(1), 45-71.

Bass, H. (2012). SMEs development in the 21st century. Routledge: New York. USA.

Cant, M.C., \& Wiid, J.A. (2013). Establishing the challenges affecting South African SMEs, International Business \& Economics Research Journal, 12 (6), 707-716.

Chinamasa, P. (2016). Zimbabwe interim poverty reduction strategy paper. (2016-2018). Ministry of Finance \& Economic Development, Zimbabwe

Delgado, M., Porter, M.E, \& Stern, S. (2014). Defining clusters of related industries. U.S. Cluster Mapping Project.USA: University of Minnesota.

FAO. (2017). The future of food and agriculture, trends and challenges; Food and Agriculture Organization of the United Nations: Rome, Italy.

Finmark Trust. (2012). Finscope MSME survey, Zimbabwe.

Food and Nutrition Council. (2014). Zimbabwe national nutrition strategy. Harare.

Fornahl, D., Hassink, R. \& Menzel M, P. (2015). Broadening our knowledge on cluster evolution. European Planning Studies, 23(10):1921-1931.

Gancarczyk, M. (2015). Enterprise- and industry-level drivers of cluster evolution and outcomes for clusters in developed and less developed countries. Journal of European Planning Studies, 11(4), 3-24.

Hervas Oliver, J.L., Gonzalez, G., Caja, P., \& Sempere-Ripoll, F. (2015). Clusters and industrial districts: Where is the literature going? Identifying emerging sub-fields of research. European Planning Studies, 23(9), 1827-1872.

ILemona, A. (2013). Alleviating poverty through the use of entrepreneurship skills acquisition in Kogi State, Nigeria. International Open Journal of Economics, 1(2), 14-23.

Jason, A. (2012). Assessment of agribusiness SMEs in Malawi assessment of small and medium enterprises in the agriculture sector and improved access to finance in Malawi. Kadale Consultants. Malawi: USAID.

Kamoyo, M., Mavhima, F. and Muranda, Z. (2014). Cluster approach to microenterprise development: A comparative study of clustered and isolated wooden furniture enterprise in Zimbabwe. Journal of Sustainable Development in Africa, 16(5).

Katua .N. T. (2014).The role of SMEs in employment creation and economic development in selected countries. International Journal of Education and Research, 2(12), 461-472. 
Le Roux, I., \& Bengesi, K. M. (2014). Dimensions of entrepreneurial orientation and small and medium enterprise performance in emerging economies. Development Southern Africa, 31(4), 606-624.

Mangudya, J. P. (2017). Stimulating economic development and bolstering confidence. Monetary Policy Statement January 2017. Harare: Reserve Bank of Zimbabwe.

Ministry of Agriculture, Mechanization and irrigation development. (2014). Second Round Crop and Livestock Assessment Report.

Mkansi, M., \& Acheampong, E. A. (2012). Research philosophy debates and classifications: Students dilemma. Electronic Journal of Business Research Methods, 10(2), 132-140.

Nyamutowa, C., Masunda, S., \& Mupaso, N. (2014). Assessing the readiness of Zimbabwe in adoption of an agricultural commodity and derivatives market. A Review Paper. Midlands State University. Journal of Science, Agriculture and Technology, 5(1), 95-110.

OECD. (2016). Sustainable productivity development in agriculture: Trends and policy performance. Better policies for better lives. Meeting of Agriculture Ministers, 7-8 April, Paris.

Saunders, M., Lewis, P., and Thornhill, A. (2013). Research methods for business students.7th Ed. Harlow: Prentice Hall.

Silverman, D. (2013). Doing qualitative research: A Practical Handbook, 4th Edition:New York Sage Publications.

Uyarra, E., \& Ramlogan, R. (2012). The effects of cluster policy on innovation (Nesta Working Paper 12/05). Manchester: Manchester Institute of Innovation Research/Manchester Business School.

WFP. (2014). Results of exploratory food and nutrition security analysis. Harare. Policy Brief, RSiS, Nanyang University of Technology. Singapore.

Wolfe, D. A., \& Gertler, M. S. (2016). Clusters from the inside and out: Local dynamics and global linkages. Urban Studies, 41(5-6), 1071-1093.

ZimVac. (2013). Rural livelihoods assessment draft report. Harare, Zimbabwe.

\section{Appendix: 1}

\section{A Survey Questionnaire On Clustering Agricultural SMEs \\ Declaration by Respondent}

I consent to taking part in the completion of the questionnaire.

Respondent artificial signature

\section{Answer all questions; please consign an (X)/tick where appropriate.}

Section A:Respondent Background

1 . Put an X to show your role within your SME?

Role.....

2. How long did it take you to be placed into a cluster by your relevant authorities?

\section{Section B:Agricultural SMEs}

Now answer the following questions (3-6) using a scale of 1- 4 where 4= Strongly Agree; 3 Agree; $2=$ Strongly Disagree; $1=$ Disagree.

\begin{tabular}{|l|l|l|l|l|}
\hline $\begin{array}{l}\text { From your own experience do clustering agricultural SMEs improve } \\
\text { their market share development and competitiveness? }\end{array}$ & 1 & 2 & 3 & 4 \\
\hline $\begin{array}{l}\text { To what extent does clustering influence the performance and } \\
\text { development (development) of your SME to ensure food security is } \\
\text { attained? }\end{array}$ & & & & \\
\hline $\begin{array}{l}\text { Does clustering stimulate community development and } \\
\text { industrialization? }\end{array}$ & & & & \\
\hline Does clustering spur entrepreneurial development? & & \\
\hline
\end{tabular}

